\title{
In vivo Evaluation of Antimicrobial Effect of Propolis, Miswak, Green Tea Compared to Sodium Hypochlorite and Chlorhexidine as Root Canal Irrigants in Necrotic Infected Single Rooted Teeth
}

\author{
Abeer M. Darag', Dalia M. Fayyad², Abd El Azeem M. El Gammal³, \\ Ashraf A. Soliman ${ }^{*}$ \\ 'Department of Endodontics, Faculty of Dentistry, Tanta University, ${ }^{2}$ Department of Endodontics, Faculty of \\ Dentistry, Suez Canal University, Department of Bacteriology, Mycology and Immunology, Faculty of Veteri- \\ nary Medicine, Suez Canal University, Egypt
}

\begin{abstract}
Aim: To assess clinically, radiographically and laboratory the antimicrobial effect of propolis, miswak, green tea, sodium hypochlorite and chlorhexidine on necrotic teeth with apical peridontitis. Materials and Methods: A total of 50 patients with chronic apical periodontitis in a permanent mature single-rooted tooth with a necrotic pulp were included. Root canals were instrumented using Revo S NiTi files and different irrigants: Sodium hypochlorite 3\% ( $\mathrm{NaOCl}), 2 \%$ chlorhexidine ( $\mathrm{CHX}), 20 \%$ ethanolic extract of Egyptian propolis, 20\% ethanolic extract of Miswak and 20\% ethanolic extract of Green tea. Root canals were sampled before (S1) and immediately after the chemomechanical preparation (S2). The samples (S1\&S2) were transferred for culturing and incubation (both aerobically and anaerobically). The patients were re-evaluated both clinically and radiographically after 1, 3 and 6 months). Results: CHX group showed the highest mean \% reduction in $\log _{10}$ of anaerobic bacterial counts (95.5 \pm 8.0 ). CHX group showed non-statistically significant difference from $\mathrm{NaOCl}(86.2 \pm 16.7)$ and Propolis (84.4 \pm 9.7$)$. Miswak group showed statistically significantly lower mean \% reduction (75.6 \pm 19.1$)$ than $\mathrm{CHX}$ group and $\mathrm{NaOCl}$ group, but non-statistically significant difference from Propolis group. Green tea group showed the lowest statistically significant mean \% reduction in $\log _{10}$ of anaerobic bacterial counts (50.10 \pm 10.35$)$. Conclusion: Propolis, Salvadora Perisca and green tea alcoholic extracts at $20 \%$ concentration showed considerable antimicrobial effect against chronic apical periodontitis microbes generally and $\mathrm{E}$. faecalis definitely.
\end{abstract}

Keywords: E.faecalis, herbal irrigants, chronic apical periodontitis.

\section{Introduction}

Complete elimination of microflora from the root canal system is of utmost importance for the success of root canal therapy, which is dependent on mechanical preparation, irrigation, microbial control and complete obturation of root canals. When endodontic treatment is performed under aseptic conditions and according 
to accepted clinical principles, the success rate is generally high(1). The most popular endodontic irrigant is sodium hypochlorite $(\mathrm{NaOCl})$, which has been used for well over four decades. Although it is an effective antimicrobial agent and an excellent organic solvent, it is known to be highly irritant to the periapical tissues, mainly at high concentrations. For this reason the search for another irrigant with a lower potential to induce adverse effects is desirable ${ }^{(2)}$. Chlorhexidine gluconate $(\mathrm{CHX})$ has also been recommended as a root canal irrigant and many studies have demonstrated its broad spectrum antimicrobial action, substantivity, and low grade of toxicity. However the inability of chlorhexidine to dissolve pulp tissue has been a problem, some attempts were made to solve this deficiency by the combined use of $\mathrm{NaOCl}$ and $\mathrm{CHX}^{(3)}$. Propolis is a natural non-toxic beehive product, which is used for building and restoration of the honey comb. In the hive, propolis act as a biocide, being active against the invasive bacteria, fungi and even invading larvae. Other biological activities have also been depicted for propolis, including antibacterial, antifungal, antiviral, antitumor, immunemodulation. Anti-bacterial activity of propolis ethanolic extract of different geographic origin against oral pathogens has been studied by several authors ${ }^{(4)}$. Miswak is mainly used to describe the stick, which is used for cleansing the teeth. Arak is the plant from which Miswak is derived (Salvadora persica). Many studies have been carried out on different types of chewing sticks focused mainly on antimicrobial activity of these sticks(5). Green tea is a non-fermented tea, and contains more Catechins, than black tea or oolong tea. Catechins are strong antioxidants. In addition, its content of certain minerals and vitamins increases the antioxidant potential of this type of tea. Green tea has been consumed throughout the ages in India, China, Japan and Thailand. Recent human studies suggested that green tea contributes to overall oral health. It has been used in dentistry and has a promising role in future ${ }^{(6)}$.

\section{Materials and Methods}

Total of fifty patients-males and females- with chronic apical periodontitis in a permanent mature singlerooted tooth with a necrotic pulp were included in this study, their ages ranged from 18-60 years. Each of them was diagnosed for being healthy, not suffering from any systemic illness. The 50 subjects were randomly divided into 5 groups of 10 patients according to the type of irrigant that was used as follow: Group 1: 3\% sodium hypochlorite, Group 2: $2 \%$ chlorhexidine, Group 3: 20\% ethanolic extract of miswak, Group 4: 20\% ethanolic extract of propolis, Group 5: $20 \%$ ethanolic extract of green tea. After rubber dam isolation and access opening, the first microbiological samples (S1) (baseline) were collected by sterile paper points for 1 minute. The paper points were placed into transport media (Thioglycollate broth) for microbial culturing. The root canals were instrumented with Revo $S \mathrm{NiTi}$ rotary files with a with crowndown technique. The root canals were irrigated after each file size with $3 \mathrm{ml}$ of the respective solution related to each group of patients for about 30 seconds. Then the canals were finally irrigated with $10 \mathrm{ml}$ of the respective irrigant solution, dried with 
sterile paper points, and a sample of its contents was taken again (S2). The root canals of all groups were obturated with gutta percha points and resin based sealer ( $\mathrm{AH}$ plus) at the same visit then a periapical $x$-ray film was taken immediately post obturation (base line image). The samples (S1\&S2) were transferred for culturing and incubation. A $0.1 \mathrm{ml}$ of thioglycollate broth will be inoculated on two plate count agar plates. One Petri plate was incubated aerobically for 24 hours and the other Petri plate was incubated anaerobically for 48 hours. After the incubation period, the plates were examined and the colonies were counted with digital colony counter. The patients were returned to the clinic for evaluation both clinically and radiographically after 1 month, 3 months and 6 months.

\section{Results}

There was a statistically significant decrease in mean $\log _{10}$ CFU of anaerobic bacterial counts after chemomechanical preparation for all tested irrigation solutions. There was a statistically significant decrease in mean $\log _{10}$ CFU of anaerobic bacterial counts after chemomechanical preparation for all tested irrigation solutions.

Table 1: Mean $\log _{10}$, standard deviation (SD) values and results of comparison between $\log _{10}$ CFU of anaerobic bacterial counts before and after chemomechanical preparation within each group

\begin{tabular}{|l|c|c|c|c|c|}
\hline \multirow{2}{*}{} & \multicolumn{2}{|c|}{$\begin{array}{c}\text { Before prepara- } \\
\text { tion }\end{array}$} & \multicolumn{2}{|c|}{$\begin{array}{c}\text { After } \\
\text { preparation }\end{array}$} & \multirow{2}{*}{ P-value } \\
\cline { 2 - 5 } & $\begin{array}{c}\text { Mean } \\
\log _{10}\end{array}$ & SD & $\begin{array}{c}\text { Mean } \\
\log _{10}\end{array}$ & SD & \\
\hline $\mathrm{NaOCl}$ & 5.34 & 0.45 & 2.55 & 2.80 & $0.028^{*}$ \\
\hline $\mathrm{CHX}$ & 5.49 & 0.61 & 1.43 & 2.22 & $0.027^{*}$ \\
\hline Propolis & 4.91 & 0.49 & 3.56 & 1.78 & $0.027^{*}$ \\
\hline Miswak & 5.51 & 0.29 & 2.66 & 2.91 & $0.028^{*}$ \\
\hline Green tea & 5.25 & 0.26 & 4.23 & 2.10 & $0.028^{*}$ \\
\hline
\end{tabular}

*: Significant at $P \leq 0.05$

\section{Discussion}

In our clinical study, $\mathrm{CHX}$ group showed the best antimicrobial activity among all groups against both aerobic as well as anaerobic endodontic pathogenes. This comes in accordance with Ohara et al. (1993) who reported that antibacterial effect of $\mathrm{CHX}$ was the best among six irrigants against anaerobic bacteria ${ }^{(7)}$. Moreover, Jeansonne and White $(1994)^{(8)}$ reported that $2 \% \mathrm{CHX}$ was more effective in reducing the number of positive cultures and CFU than $5.25 \%$ sodium hypochlorite.
The findings of our study were also parallel with Ayhan et al. (1999) who concluded that $\mathrm{CHX}$ was effective in endodontic infections $(9)$, and Zamany et al. (2003) who found that at the end of the first appointment, $2 \% \mathrm{CHX}$ was significantly more effective than the saline control in providing a bacteria-free root canal(4). Moreover, Zamany et al. (2003) showed that a $2 \% \mathrm{CHX}$ solution, when used as a final irrigant, significantly decreased bacterial loads in root canals that had been irrigated with $\mathrm{NaOCl}$ during canal preparation ${ }^{(10)}$. Again, Ercan et al. (2004) stated that $\mathrm{CHX}$ and $\mathrm{NaOCl}$ 
were significantly effective in reduction of the microorganisms in the teeth with necrotic pulp, periapical pathologies, or both, and could be used successfully as a root canal irrigant ${ }^{(11)}$. Also, Siqueira et al. (2007) showed that $\mathrm{CHX}$ based protocol was highly effective in reducing the bacterial populations within the infected root canals rendering most canals free of cultivable bacteria(12). Besides, Ferraz et al. (2007) concluded that $2 \% \mathrm{CHX}$ in comparison with all concentrations of $\mathrm{NaOCl}$ had more anti- bacterial effect on gram-negative anaerobic bacteria(13). This finding may be explained by the fact that $\mathrm{CHX}$ has a wide antimicrobial spectrum and it is effective against both Gram-positive and Gram-negative bacteria as well as yeasts ${ }^{(14)}$, Chlorhexidine acts by electrostatic interaction as it is positively charged and the bacterial wall is negatively charged, where interaction will happen and increase the cell wall coating allowing bacterial cytoplasm coagulation and results in cell death ${ }^{(15)}$.

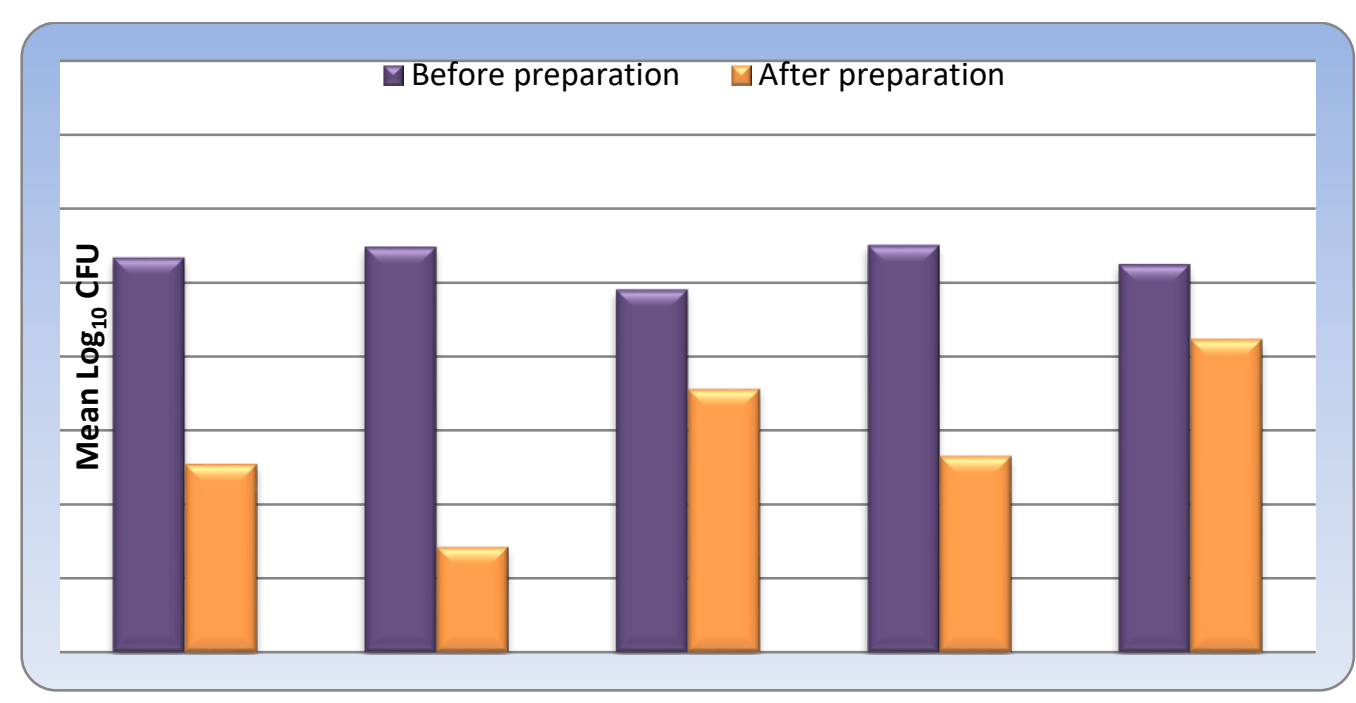

Figure 1: Bar chart representing changes after chemomechanical preparation in mean $\log _{10}$ CFU of anaerobic bacterial counts

Moreover, $\mathrm{CHX}$ was used in the present study in $2 \%$ concentration which could be a possible reason of great inhibition of the microorganisms because Krithikadatta et al(16) demonstrated that this dosage may increase diffusion of the irrigant into the dentinal tubules. Furthermore, $\mathrm{CHX}$ can bind to surrounding tissues and then be released again slowly at therapeutic levels over extended periods of time in a phenomenon known as substantivity(12). On the other hand, a randomized clinical trial by Ringel et $\mathrm{al}^{(17)}(1982)$ concluded that $\mathrm{NaOCl}$ was found to be significantly more efficient than $\mathrm{CHX}$ in obtaining negative cultures. Also a study conducted by Yamashita et al. (2003) $)^{(18)}$ demonstrated that root canal cleaning by $\mathrm{CHX}$ was inferior compared with the cleaning by $\mathrm{NaOCl}$ with and without EDTA, which was explained by the inability of $\mathrm{CHX}$ to remove smear layer (18). The results of this study also indicated that $2 \% \mathrm{CHX}$ is more effective than propolis as an antimicrobial endodontic irrigant. The results also indicated that propolis have antibacterial effect on the growth of aerobic and anaerobic bacteria when used as an endodontic irrigant but, it is significantly more effective in aerobic than anaerobic condition. The antimicrobial effect 
of propolis in this study were similar to those obtained by others who have evaluated the inhibitory effect of propolis solution on bacterial growth (Ahangari et al., 2009)(19); Mohammadzade et al., 2007(20). Soley et al. (2011) also concluded that propolis has antimicrobial activity against $E$. faecalis and C. albicans and is an effective intracanal irrigant in eradicating $E$. faecalis and C. albicans ${ }^{(21)}$. In another study focused on the chemical composition, oral toxicity and antibacterial activity of Iranian propolis on male rats, Mohammadzadeh et al. (2007) stated that this substance has no significant clinical toxicity and is capable of preventing the growth of all the tested microorganisms including bacteria and fungi(20). Bruschi et al. (2006) found that propolis has an inhibitory effect on microorganism of oral importance (E. faecalis, Streptococcus salivarius, Streptococcus sanguinis, Streptococcus mitis, Streptococcus mutans, Streptococcus sobrinus, C. albicans and Latobacillus casei) $^{(22)}$. Ferreira et al. (2007) also found that propolis had an antibacterial effect on selected endodontic anaerobic bacteria (Prevotella nigrescens, Fusobacterium nucleatum, Actinomyces israelii, Clostridium perfringens and E. faecalis) ${ }^{(23)}$. Also our results were in agreement with Kayaoglu et al (2011) (24) who concluded that propolis samples were antimicrobially effective; however, their activity did not exceed CHX. Miswak group exhibited significant antimicrobial activity against both aerobic as well as anaerobic bacteria. Miswak group showed statistically significantly lower mean \% reduction ( $75.67 \pm 19.16$ -anaerobic bacterial counts) than $\mathrm{CHX}$ group and $\mathrm{NaOCl}$ group, but non-statistically significant difference from Propolis group. Previous studies have reported that Miswak extracts were effective against $S$. mutans and E. faecalis, even using low extract concentrations. Almas and Stakiw reported that the aqueous extract $(50 \% \mathrm{v} / \mathrm{v})$ of the chewing sticks Miswak inhibited the growth of E. faecalis, with $2 \mathrm{~mm}$ as a diameter of inhibition zone ${ }^{(25)}$. In 2003, Alali and Al-Lafi reported that the volatile oil of Jordanian Miswak stems exhibited potent antibacterial activity against both Gram-positive and Gram-negative bacteria(26). Recently, Al-Bayati and Sulaiman tested the activity of aqueous and methanol extracts of Iraquian Miswak against seven isolated oral pathogens. The strongest antibacterial activity was observed using the aqueous extract against E. faecalis(27). As reported by Sher et al. the extract of Miswak was found to be effective against S. pyrogenis, E. faecalis, $P$. aeruginosa and Lactobacillus acidophilus ${ }^{(28)}$.

Table 2: Mean $\log _{10}$, standard deviation (SD) values and results of comparison between $\log _{10}$ CFU of aerobic bacterial counts before and after preparation within each group (in vivo study)

\begin{tabular}{|l|c|c|c|c|c|}
\hline \multirow{2}{*}{} & \multicolumn{2}{|c|}{$\begin{array}{c}\text { Before } \\
\text { preparation }\end{array}$} & \multicolumn{2}{c|}{$\begin{array}{c}\text { After } \\
\text { preparation }\end{array}$} & \multirow{2}{*}{ P-value } \\
\cline { 2 - 5 } & $\begin{array}{c}\text { Mean } \\
\log _{10}\end{array}$ & SD & $\begin{array}{c}\text { Mean } \\
\log _{10}\end{array}$ & SD & \\
\hline $\mathrm{NaOCl}$ & 5.59 & 0.29 & 0.67 & 1.63 & $0.028^{*}$ \\
\hline $\mathrm{CHX}$ & 5.66 & 0.37 & 0.00 & 0.00 & $0.028^{*}$ \\
\hline Propolis & 5.83 & 0.27 & 2.05 & 2.25 & $0.028^{*}$ \\
\hline Miswak & 6.05 & 0.33 & 2.93 & 2.28 & $0.028^{*}$ \\
\hline Green tea & 5.64 & 0.38 & 3.05 & 2.36 & $0.028^{*}$ \\
\hline
\end{tabular}

*: Significant at $P \leq 0.05$ 


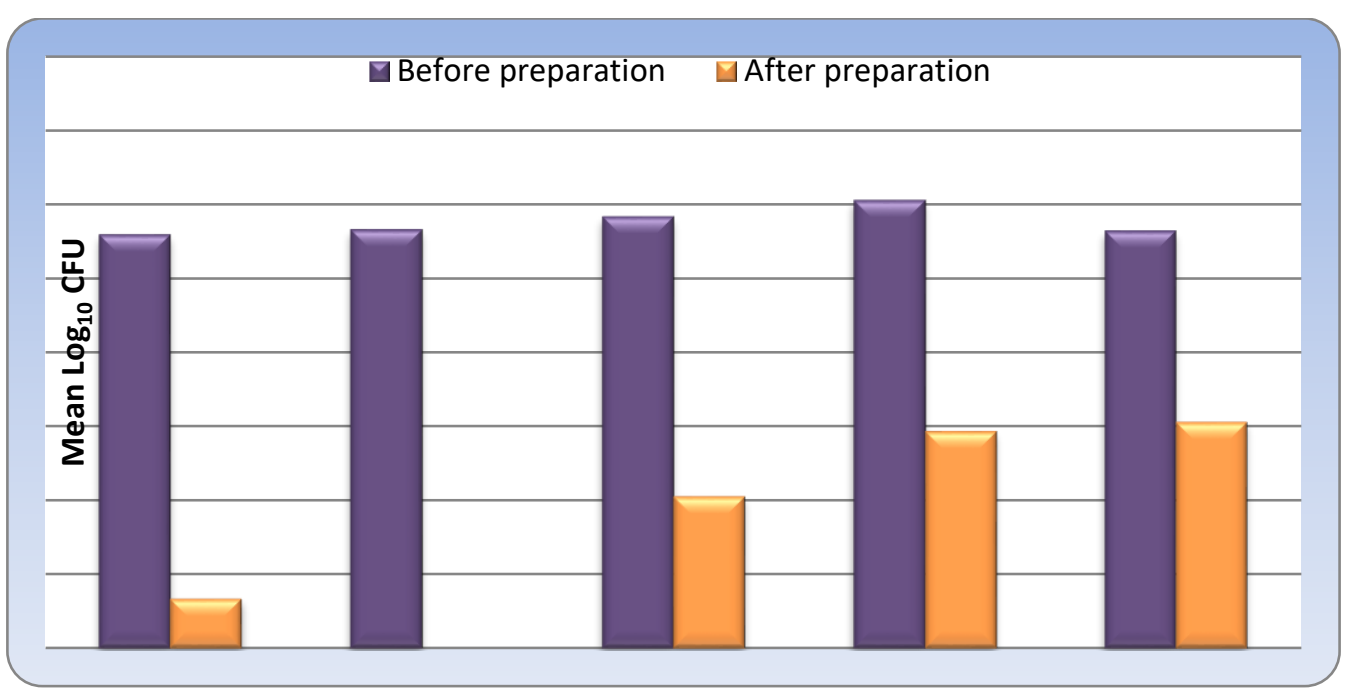

Figure 2: Line chart representing changes after chemomechanical preparation in mean $\log _{10}$ CFU of aerobic bacterial counts (In vivo study)

On the contrary Mehdi et al. (2010) compared the antimicrobial effects of Persica ${ }^{\circledR}$ and $\mathrm{CHX}$ with $\mathrm{NaOCl}$ on $E$. faecalis and Candida albicans. The results showed that the microorganisms were very sensitive to $\mathrm{NaOCl}$ but there was not any sensitivity to Persica, totally used concentrations had less effect than Sodium hypochlorite (29). The present study showed that green tea hydroalcoholic extract have antibacterial effect against both aerobic as well as anaerobic bacteria. Green tea group showed the lowest \% reduction in $\log _{10}$ of aerobic and anaerobic bacterial counts than the other groups. Green tea group showed a statistically significant difference from $\mathrm{NaOCl}$ and $\mathrm{CHX}$. This was in agreement with other studies; Garg et al. investigated the antibacterial effect of green tea polyphenols compared with 5.25\% $\mathrm{NaOCl}$. According to the obtained results, GTPs exhibited significant antimicrobial activity but this activity was statistically significant difference from $\mathrm{NaOCl}^{(30)}$. Trilaksana \& Saraswati investigated the efficacy of green tea leaf extract with $\mathrm{NaOCl}$ $2.5 \%$ as an alternative solution for root canal irrigation; they also stated that $\mathrm{NaOCl} 2.5 \%$ have superior antibacterial effect compared to green tea leaf extract(31). Unlike our study, Martina et al concluded that green tea extract showed antibacterial activity which was similar to that of the $2 \%$ CHX Martina et al. 2013(32). Such weak antibacterial action of green tea migh be due to use of low concentration, Noormandi and Dabaghzadeh showed that not only does antimicrobial activity of green tea increased by increasing the concentration, but also that at the same concentrations with an increase in the amount of the substance, antimicrobial activity of the compound increases as well(33).

\section{Conclusion}

Propolis, Salvadora Perisca and green tea alcoholic extracts at $20 \%$ concentration showed considerable antimicrobial effect against chronic apical periodontitis microbes generally and E. faecalis definitely. Thus, they offer a promising natural antimicrobial alternative and may serve as a new endodontic irrigants. 


\section{References}

1. Möller ÅJ, Fabricius L, Dahlén G, Ohman AE, Heyden G. Influence on periapical tissues of indigenous oral bacteria and necrotic pulp tissue in monkeys. Scand $\mathrm{J}$ Dent Res 1981; 89(6): 475-84.

2. Haapasalo $M$, Unni $E$, Zandi $H$, Coil J. Eradication of endodontic infection by instrumentation and irrigation solutions. Endodontic Topics 2005; 10: 77-102.

3. Siqueira JF Jr, Rôças IN. Clinical implications and microbiology of bacterial persistence after treatment procedures. J Endod 2008; 34(11): 1291-1301.

4. Sundqvist G. Bacteriological studies of necrotic dental pulps. 1976.

5. Fabricius L, Dahlén G, Ohman AE, Möller AJ. Predominant indigenous oral bacteria isolated from infected root canals after varied times of closure. Scand J Dent Res 1982; 90(2): 134-44.

6. Sundqvist G, Johansson E, Sjögren U. Prevalence of black pigmented bacteroides species in root canal infections. J Endod 1989; 15(1): 13-9.

7. Ohara PK, Torabinejad $M$, Kettering JD. Antibacterial effects of various endodontic irrigants on selected anaerobic bacteria. Endodontics and Dental Traumatology 1993; 9:95-100.

8. Jeansonne MJ, White RR. A Comparison of $2 \%$ Chlorhexidine gluconate and $5.25 \%$ sodium hypochlorite as antimicrobial endodontic irrigants. J Endod 1994; 20(6):276-78.

9. Ayhan $H$, Sultan $N$, Cirak $M$, Ruhi $M Z$, Bodur H. Antimicrobial effects of various endodontic irrigants on selected microorganisms. Int Endod J 1999; 32 (2):99102.

10. Zamany A, Safavi K, Spangberg LSW. The effect of Chlorhexidine as an endodontic disinfectant. Oral Surg Oral Med Oral Path 2003; 96(5):578-81.

11. Ercan E, Ozekinci T, Atakul F, Gül K. Antibacterial activity of $2 \%$ chlorhexidine gluconate and $5.25 \%$ Sodium Hypochlorite in infected root canal: In vivo study. J Endod 2004; 30(2):84-7.

12. Siqueira JF Jr, Rocas IN, Paiva SS, Guimaraes-Pinto T, Magalhaes $\mathrm{KM}$, Lima KC. Bacteriologic investigation of the effects of sodium hypochlorite and chlorhexidine during the endodontic treatment of teeth with apical periodontitis. Oral Surg Oral Med Oral Pathol Oral Radiol Endod 2007; 104(1);122-30.

13. Ferraz CC, Gomes BP, Zaia AA, Terixeia FB, Souza-Filho FJ. Comparitive study of antimicrobial efficacy of chlorhexidine gel, chlorhexidine solution and sodium hypochlorite as endodontic irrigants. Braz Dent J 2007; 18(2):294-8.

14. Shahani MN, Subba Reddy VV. Comparison of antimicrobial substantivity of root canal irrigants in instrumented root canals up to 72 h: an in vitro study. J Indian Soc Pedod Prev Dent 2011; 29(1):2833.

15. Rocas IN, Siqueira JF Jr. Comparison of the in vivo antimicrobial effectiveness of sodium hypochlorite and chlorhexidine used as root canal irrigants: A molecular microbiology study. J Endod 2011; 37(2): 143-50.

16. Krithikadatta J, Kottoor J, Karumaran CS, Rajan G. Mandibular first molar having unusual mesial root canal morphology with contradictory cone-beam computed tomography findings: A case report. J Endod 2010; 36(10)1712-6.

17. Ringel $A M$, Patterson SS, Newton $\mathrm{CW}$, Miller $\mathrm{CH}$, Mulhern JM. In 
vivo evaluation of chlorhexidine gluconate solution and sodium hypochlorite solution as root canal irrigants. J Endod 1982; 8(5): 200-4.

18. Yamashita JC, Tanomaru M, Filho, Leonardo MR, Rossi MA, Silva LA. Scanning electron microscopic study of the cleaning ability of chlorhexidine as a root-canal irrigant. Int Endod J 2003; 36(6):391-4.

19. Ahangari Z, Eslami G, Koosedghi $\mathrm{H}$, Ayatolahi A. Comparative study of antibacterial activity of propolis and $\mathrm{Ca}(\mathrm{OH}) 2$ against lactobacillus, enterococcus faeacalis, peptostreptococus and Candida albicans. JIDA 2009; 21:50-6.

20. Mohammadzadeh S, Shariatpanahi $M$, Hamedi $M$, Ahmadkhaniha R, Samadi N, Ostad SN. Chemical composition, oral toxicity and antimicrobial activity of Iranian propolis Food Chemistry 2007; 103: 1097-1103.

21. Arslan S, Ozbilge $H$, Kaya EG, Er O. In vitro antimicrobial activity of propolis, BioPure MTAD, sodium hypochlorite, and chlorhexidine on Enterococcus faecalis and Candida albicans. Saudi Med. J 2011; 32(5):479-83.

22. Bruschi ML, Lara $\mathrm{EH}$, Martins $\mathrm{CH}$, et al. Preparation and antimicrobial activity of gelatin microparticles containing propolis against oral pathogens. Drug Dev Ind Pharm 2006; 32(2):229-38.

23. Ferrari PH, Cai S, Bombana AC. Effect of endodontic procedures on enterococci, enteric bacteria and yeasts in primary endodontic infections. Int Endod J 2005; 38(6):372-80.

24. Kayaoglu $G$, Ömürlü $H$, Akca $G$, et al. Antibacterial activity of propolis versus conventional endodontic disinfectants against Enterococcus faecalis in infected dentinal tubules. J Endod 2011;
37(3):376-81.

25. Almas K and Stakiw JE. The effect of miswak extract from Salvadora persica stored for 18 years on microbes in vitro. Egyptian Dental Journal 2000; 46(1):227-30.

26. Alali F, Al-Lafi T. GC-MS analysis and bioactivity testing of the volatile oil from the leaves of the toothbrush tree Salvadora persica L. Nat Prod Res. 2003; 17(3):189-94.

27. Al-Bayati FA, Sulaiman KD. In vitro antimicrobial activity of Salvadora persica L. extracts against some isolated oral pathogens in Iraq.Turkish Journal of Biology 2008; 32(1): 57-62.

28. Sher H, Al-yemeni MN, Wijaya L. Ethnobotanical and antibacterial potential of Salvadora persica: A well-known medicinal plant in Arab and Unani system of medicine. J Med Plants Res 2011; 5(7):1224-29.

29. Mehdi M, Khorasani Y, Assar S and Hoseini OR. Comparison of antimicrobial effects of persica and chlorhexidine with sodium hypochlorite on E. faecalis and candida albicans: An invitro study. J Mash Dent Sch 2010; 34:153-60.

30. Garg P, Tyagi SP, Sinha DJ, Singh UP, Malik V, Maccune ER. Comparison of antimicrobial efficacy of propolis, Morinda citrifolia,Azadirachta indica, triphala, green tea polyphenols and 5.25\% sodium hypochlorite against Enterococcus fecalis biofilm. Saudi Endod J 2014; 4:122-7.

31. Trilaksana AC and Saraswati A. Efficacy of green tea leaf extract (Camellia sinensis) with $\mathrm{NaOCl}$ 2.5\% againts Enterococcus faecalis as an alternative solution for root canal irrigation. J Dentomaxillofac Sci 2016:1(1):105-15.

32. Martina LP, Ebenezar AV, Ghani MF, Narayanan A, Sundaram M, 
Mohan AG. An in vitro comparative antibacterial study of different concentrations of green tea extracts and $2 \%$ chlorhexidine on Enterococcus faecalis. Saudi Endod J 2013; 3:120-4.

33. Noormandi A, Dabaghzadeh F. Effects of green tea on Escherichia coli as a uropathogen. J Tradit Complement Med 2014; 5(1):1520. 
